\title{
A Multiband Antenna for GSM, WLAN, S-band Radar and WiMAX Applications
}

\author{
Allin Joe D, Umamaheswari S, Sriram S.R
}

\begin{abstract}
The futuristic technologies needs the low profile and compact multiband antenna for their applications as the size of the communication devices are reducing significantly. In this manuscript, a patch antenna is intended over Flame Retardant (FR4) substrate and then Defected Ground Structure (DGS) as well as Defected Microstrip Structure (DMS) were introduced in it, which increases the number of resonant frequencies and their return loss. Coaxial feed was utilized in this plan. The designed antenna radiates efficiently for the applications like Global System for Mobile Communications (GSM) at $1.8 \mathrm{GHz}$ resonant frequency, WLAN with $2.4 \mathrm{GHz}$ resonant frequency, S-Band Radar by means of $2.9 \mathrm{GHz}$, resonant frequency and WiMAX standard by the side of $3.4 \mathrm{GHz}$ resonant frequency. High Frequency Structural Simulator (HFSS) was utilized for the simulation of the projected antenna design.
\end{abstract}

Keywords- Rectangular Patch, Defected Ground Structure (DGS), GSM, WLAN, S-Band Radar, Defected Microstrip Structure (DMS), WiMAX.

\section{INTRODUCTION}

Antenna intend forms the fundamental of any communication system [1]. Consequently, tumbling the aspect of antenna plays a major position in determining size of the communication system [2]. Antenna design engineers throughout the world are trying their best in shrinking the size of antenna by using some size reduction or optimization techniques available in the literature to make the communication system sustain [3-4].

On par with the size reduction techniques of antenna, multiband operation of antenna also helps indirectly in tumbling the aspect of the antenna as well as the communication system [5]. Certain techniques like Defected Ground Structure (DGS) as well as the Defected Microstrip Structure (DMS) will persuade the multiband behavior in a solitary antenna that reduces effective size of the antenna significantly [6]. Using these techniques on a rectangular patch antenna, the antenna is intended to operate on GSM, WLAN, S-Band Radar and WiMAX communication systems [7].

\section{PROPOSED ANTENNA DESIGN}

The projected antenna is a multiband compact antenna for GSM, WLAN, S-Band Radar and WiMAX applications. A rectangular patch antenna is designed by means of HFSS software based on the following design equations (1-6) [810]. The Dielectric constant value of the substrate is $\varepsilon_{r}$. The height of the dielectric substrate is $h$. The width of the

Revised Manuscript Received on 14 August, 2019.

Allin Joe D, Electronics and Communication Engineering Department, Kumaraguru College of Technology, Coimbatore, Tamilnadu, India.

Umamaheswari $\mathbf{S}$, Electronics and Communication Engineering Department, Kumaraguru College of Technology, Coimbatore, Tamilnadu, India.

Sriram S.R, Electronics and Communication Engineering Department, Kumaraguru College of Technology, Coimbatore, Tamilnadu, India.. designed patch is given by $W$. The Effectual dielectric constant $\varepsilon_{r e}$ is found by the following equation.

$$
\begin{aligned}
& \varepsilon_{r e}=\frac{\varepsilon_{r}+1}{2}+\frac{\varepsilon_{r}-1}{2}\left[1+12 \frac{h}{W}\right]^{-\frac{1}{2}} \\
& \Delta L=0.412 \frac{\left(\varepsilon_{r e} \pm 0.3\right)\left(\frac{W}{h}+0.264\right)}{\left(\varepsilon_{r e}-0.3\right)\left(\frac{W}{h}+0.8\right)}
\end{aligned}
$$

The effectual length of the patch $\mathrm{L}_{\mathrm{e}}$ can be establish from the subsequent equation as

$$
\mathrm{L}_{\mathrm{e}}=\mathrm{L}+2 \Delta \mathrm{L}
$$

For a reverberation occurrence $f_{0}$, the effectual length of the rectangular patch antenna $\mathrm{L}_{\mathrm{e}}$ is

$$
\mathrm{L}_{\mathrm{e}}=\frac{C}{2 f_{0} \sqrt{\varepsilon_{r e}}}
$$

Reverberation occurrence $f_{0}$ for some $\mathrm{TM}_{\mathrm{mn}}$ form of rectangular patch antenna can be found by the following equation

$$
f_{0}=\frac{C}{2 \sqrt{\varepsilon_{\text {reff }}}}\left[\left(\frac{\mathrm{m}}{\mathrm{L}}\right)^{2}+\left(\frac{\mathrm{n}}{\mathrm{W}}\right)^{2}\right]^{\frac{1}{2}}(5)
$$

The $m$ and $n$ are the mode that exist beside the Length, Width of the patch antenna whereas width (W) for an effective radiation is calculated using

$$
\text { amagedW }=\frac{C}{2 f_{0} \sqrt{\frac{\left(\varepsilon_{r}+1\right)}{2}}}
$$

FR4 Substrate is utilizeded in the projected antenna intend. Coaxial feed be there for the excitation of the antenna. Two defected microstrip structures are introduced in the rectangular patch antenna for inducing the multiband behavior in the patch antenna. The dimensions of the two DMS structures are similar. The front and rear view of the designed defected microstrip patch antenna (MPA) is exposed in Figure 1 as well as in Figure 2.

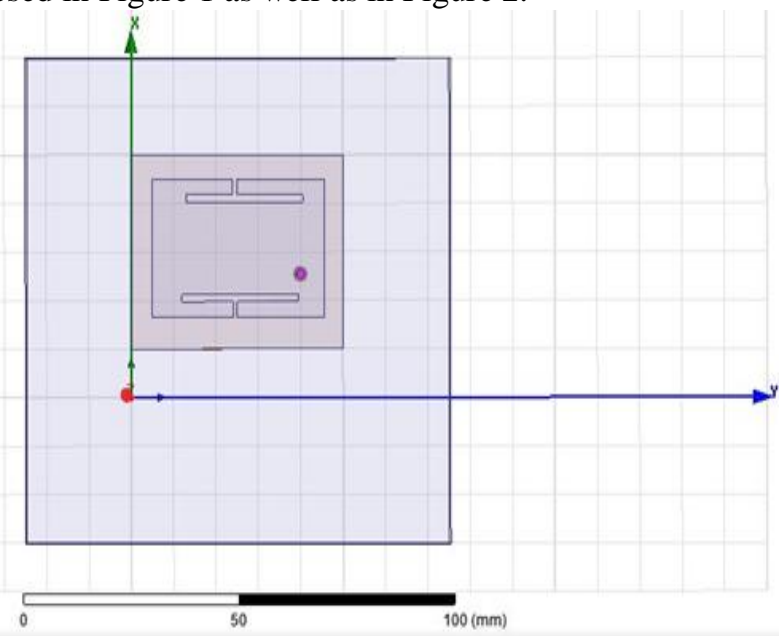

Fig. 1. Front view of Defected MPA

Published By: Blue Eyes Intelligence Engineering \& Sciences Publication 


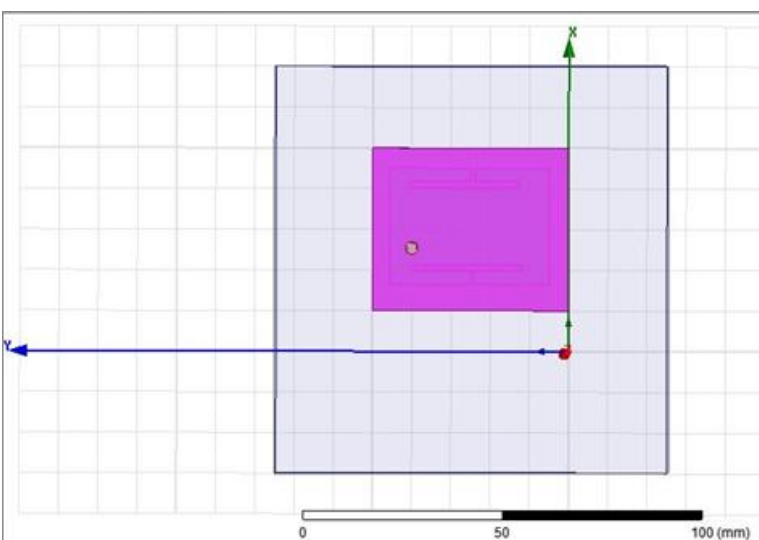

Fig. 2. Rear view of Defected MPA

\section{RESULTS AND DISCUSSION}

The return loss as well as VSWR plot for the defected MPA is exposed in Figure 3 as well as Figure 4. The resonant frequencies of the projected antenna are as follows: $1.799 \mathrm{GHz}, 2.4623 \mathrm{GHz}, 2.9598 \mathrm{GHz}, 3.4121 \mathrm{GHz}$ for the simulated defected MPA structure using HFSS.

DGS is introduced in the ground plane of the defected MPA to fine-tune the resonant frequencies as per our prerequisite. The front view and rear view of the defected ground structure in the projected antenna is exposed in Figure 5 along with Figure 6. The return loss plot values and the VSWR plot values of the projected antenna is shown in Figure 7 in addition to Figure 8

The proportions of the designed defected microstrip structures over the patch and the defected ground structures over the ground plane are accustomed towards the preferred results for the necessary global communication applications.

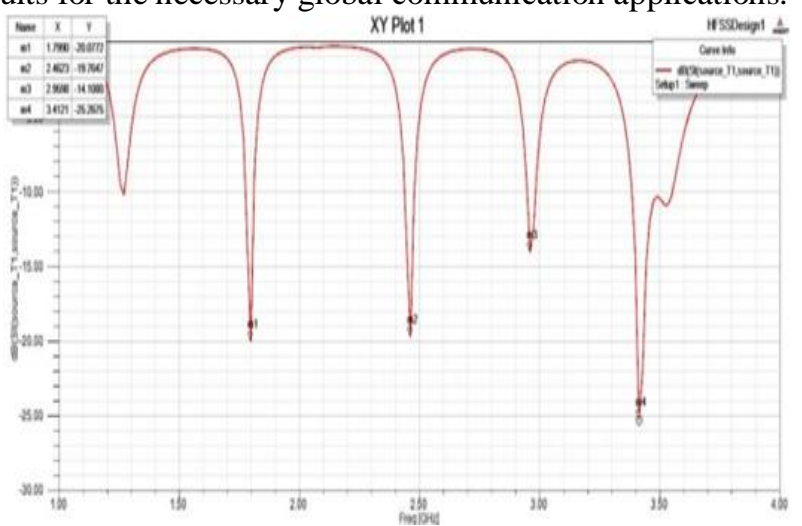

Fig. 3. Return loss plot of Defected MPA

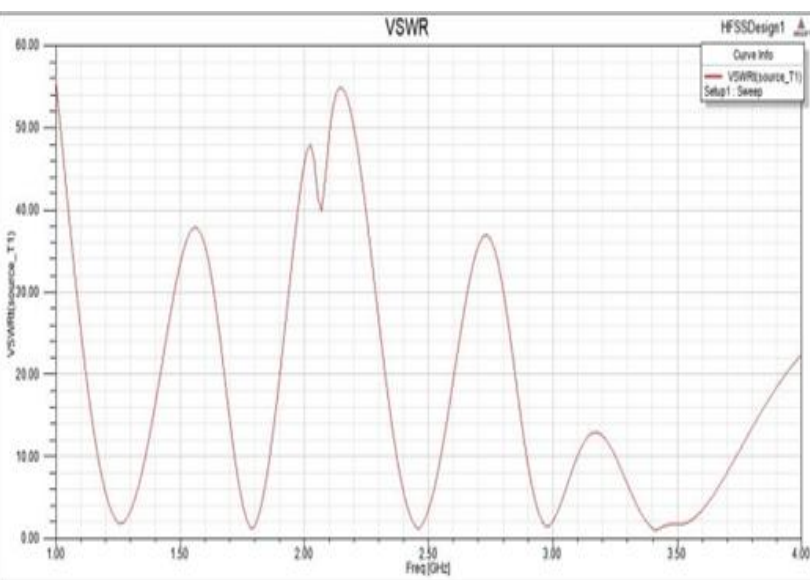

Fig. 4. VSWR plot of Defected MPA

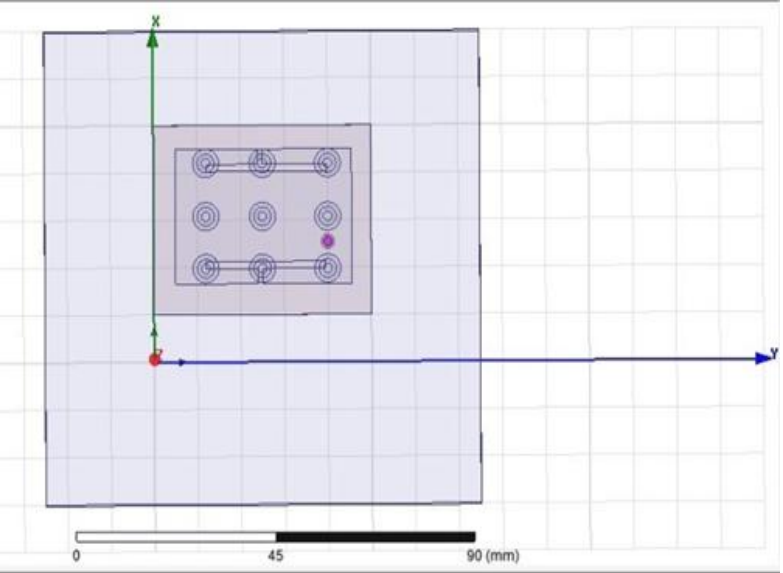

Fig. 5. Front view of introduced DGS

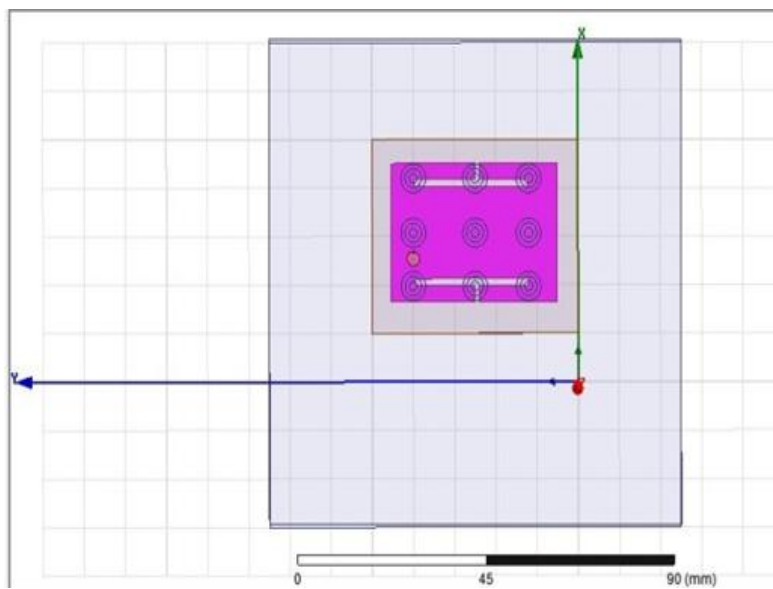

Fig. 6. Rear view of introduced DGS

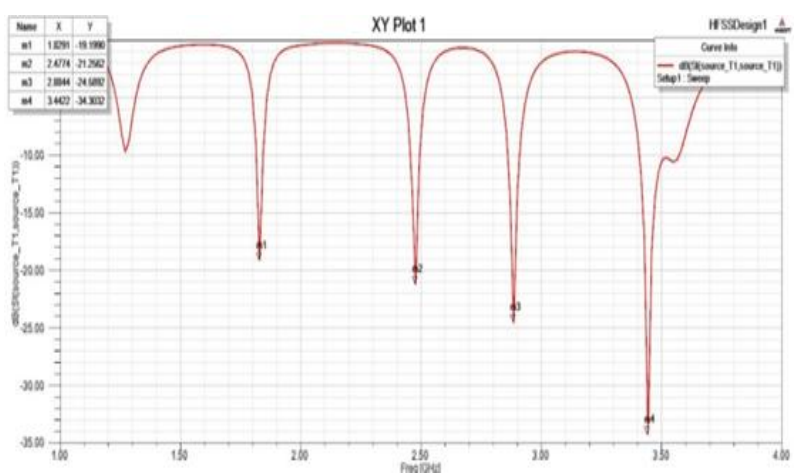

Fig. 7. Return loss plot of introduced DGS

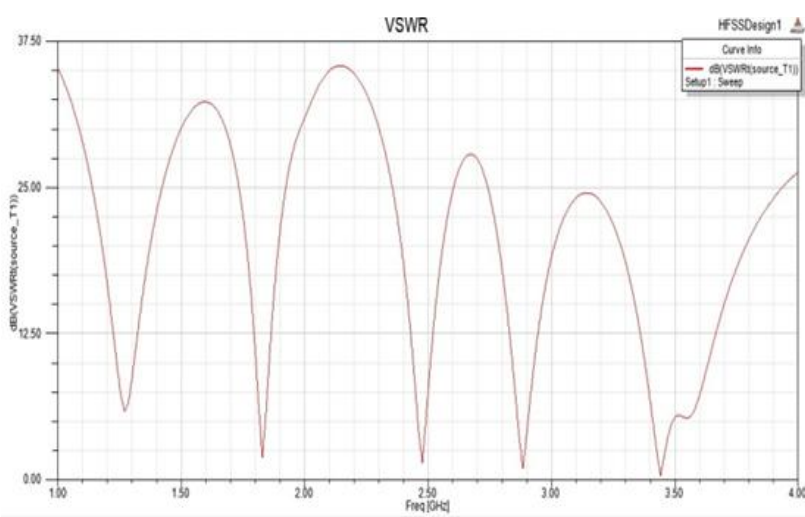

Fig. 8. VSWR plot of introduced DGS

Blue Eyes Intelligence Engineering

\& Sciences Publication 


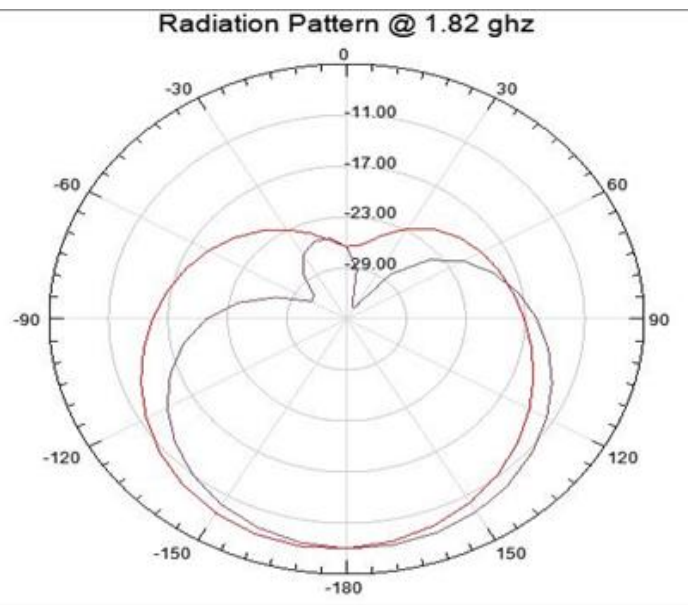

Fig. 9. Radiation pattern of designed antenna at $\mathbf{1 . 8 2}$ GHz

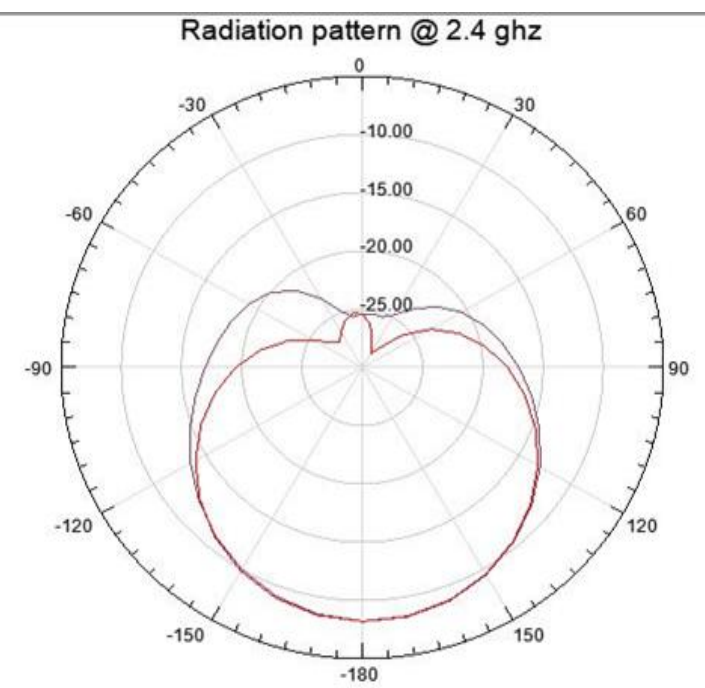

Fig. 10. Radiation pattern of designed antenna at 2.4 GHz

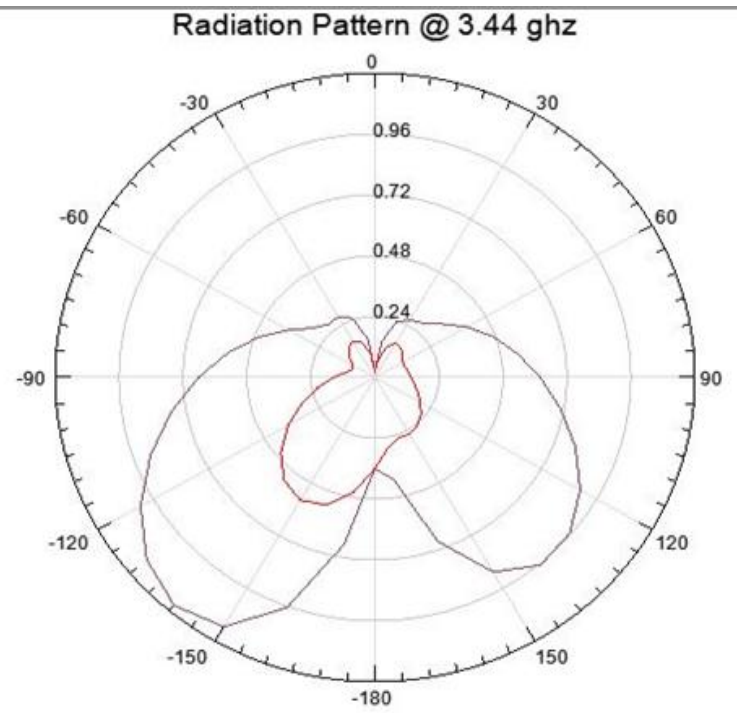

Fig. 11. Radiation pattern of designed antenna at $\mathbf{2 . 8 8}$ $\mathbf{G H z}$

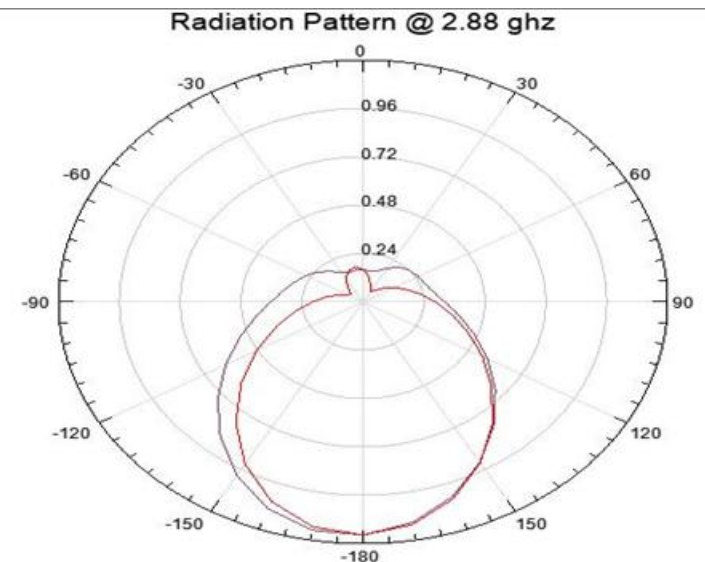

Fig. 12. Radiation pattern of designed antenna at 3.44 GHz

The proposed antenna has $-19.199 \mathrm{~dB}$ return loss value at $1.8291 \mathrm{GHz}$ resonant frequency and this is suitable for GSM communication systems, $-21.2562 \mathrm{~dB}$ returnloss value at $2.4774 \mathrm{GHz}$ resonant frequency and this is suitable for WLAN communication, $-24.5892 \mathrm{~dB}$ return loss value at $2.8844 \mathrm{GHz}$ resonant frequency and this is suitable for $\mathrm{S}$ band radar communication and $-34.3032 \mathrm{~dB}$ return loss at $3.4422 \mathrm{GHz}$ resonant frequency which is suitable for WiMAX communication standards. The bandwidth across each resonant frequency is sufficient for the preferred wireless communication systems. The return loss fewer than $-10 \mathrm{~dB}$ as well as a VSWR value less than 2 makes an antenna communication more proficient. The radiation patterns of $1.82 \mathrm{GHz}, 2.4 \mathrm{GHz}, 2.88 \mathrm{GHz}$ and $3.44 \mathrm{GHz}$ are exposed in Figure 9, Figure 10, Figure 11 and Figure 12. The emission prototypes demonstrate that the designed antenna is directional.

\section{CONCLUSION}

A compact multiband antenna for GSM, WLAN, S-band Radar and WiMAX applications are designed by introducing Defected Microstrip structures and Defected Ground Structures over the rectangular patch antenna. The projected antenna has the well definedreturnloss values and VSWR values over the matching applications.

\section{REFERENCES}

1. Allin Joe D, Pavithra P, and Dr.Rajeshkumar V "A Compact Multi-band Antenna for WLAN \& WiMAX Applications using Minkowski Fractal and Defected Microstrip Structure", International Journal of Microwave and Optical Technology (IJMOT), Vol. 12, No 3, pp. 198-203, May 2017.

2. Rajeshkumar, V., and Raghavan, S., 2015. A compact metamaterial inspired triple band antenna for reconfigurable WLAN/WiMAX applications. International Journal of Electronics and Communications, 69(1), pp. 274-280.

3. Allin Joe D, Geethpriya S, Pavithra P, and Karthikumar R, "Design of Z Shape Microstrip Patch Antenna with I Slot for UHF and GPS Applications", International Journal of Pure and Applied Mathematics, vol.117, Issue 8, pp. 105-108, 2017. 
4. Sethuramalingam, T. K., and B. Nagaraj. "A soft computing approach on ship trajectory control for marine applications." ARPN J Eng Appl Sci 10, no. 9 (2015): 4281-4286.

5. Constantine A. Balanis, 1997. Antennas Theory Analysis and Design. John Wiley\&Sons, Inc.

6. John D. Krauss, 1988. Antennas. McGraw Hill International.

7. Yi Huang and Kevin Boyle, 2008. Antennas from Theory to Practice. John Wiley\&Sons, Inc.

8. Nagaraj, B., and R. Murugananth. "Optimum tuning algorithms for PID controller-a soft computing approach." IPPTA Journal 22, no. 2 (2010): 127-130.

9. Liu, Wendong, Zhijun Zhang, Jianfeng Zheng, and Zhenghe Feng. "A novel miniaturized antenna for ISM 433MHz wireless system", 2011 IEEE Electrical Design of Advanced Packaging and Systems Symposium (EDAPS), 2011.

10. Kushwah, Vivek Singh, Shivani Jain, and Gaurav Saxena. "Design of Microstrip Patch Antenna Using Defected Microstrip Structure", 2015 Fifth International Conference on Communication Systems and Network Technologies, 2015.

11. R. P. S. Gangwar, Sanjay Dutt. "Wideband Patch Antenna for Land based Vehicles", Journal of The Institution of Engineers (India): Series B, 2016. 